\title{
Virgin coconut oil dielectrical properties as electrical insulation material
}

\author{
Siti Syafiqah Mat Sauki, Nor Asiah Muhamad, Zawani Amirah Rasid
}

School of Electrical Electronic Engineering, Universiti Sains Malaysia, Malaysia

\begin{tabular}{ll}
\hline \hline Article Info & ABSTRACT \\
\cline { 2 - 3 } Article history: & $\begin{array}{l}\text { Mineral oil played an important role as insulating liquid such as to reduce } \\
\text { failure, ageing effect, increase the life span and heat transfer agent. Mineral } \\
\text { oil had a good dielectric strength and cooling performance but it had serious } \\
\text { Received Apr 4, } 2019\end{array}$ \\
negative environmental impact like non-biodegradable, non-renewable \\
Accepted Jul 20,2019
\end{tabular}

Copyright $\left(C_{0} 2019\right.$ Institute of Advanced Engineering and Science. All rights reserved.

\section{Corresponding Author:}

Nor Asiah Muhamad,

School of Electrical Electronic Engineering,

Universiti Science Malaysia,

Nibong Tebal, 14300, Penang, Malaysia.

Email: norasiah.m@usm.my

\section{INTRODUCTION}

Transformer is an equipment that use mineral oil to serve the dual purposes, insulation and cooling medium. This is because mineral oil has a good dielectric properties yet it gives a terrible effect on the environment and it is non-biodegradable [1-7]. Due to the environmental issue, there are many researches on new biodegradable oil. The coconut oil also gain attention at tropical country due to dry and wet climate with average temperature between 21 to $30{ }^{\circ} \mathrm{C}$. Complete specification for the transformer oil can be referring to the IEC 60296 [8].With the development of technology, the scientist does the oil treatment to increase the lifespan of biodegradable oil in the transformer and reduce the maintenance cost. This coconut oil has an advantage where the rate of breakdown voltage decrease with the increasing of moisture absorption of coconut oil is very low compared to mineral oil, under similar conditions of exposure to the atmosphere. The disadvantage is it has high pour point $[4,6,9]$ which is approximately $23^{\circ} \mathrm{C}$ [10]. Thus, this study tries to look on the possibility of using virgin coconut oil (VCO).

Malaysia is one the tropical paradise country in Asia situated on the line of equator which has sunny days and rainy days throughout the year. Hence, a lot of mature coconut fruits are found throughout the Malaysia and become the authentic resources known as the "tree of one thousand uses". When consider the local circumstance, the virgin coconut oil should be employ and undergo the process of treatment to make it as an alternative to transformer oil. There is a difference between antioxidants content in regular coconut oil 
and virgin coconut oil (VCO). Research that has been conducted show VCO has the highest breakdown voltage, lowest moisture and viscosity compared to palm oil and coconut oil [1,5]. The percentage of saturated fat in VCO is $90 \%$ which is very high [5, 6]. It means that when the saturated fat is very high, the pour point and kinematic viscosity also could be very high.

There are several important properties such as dielectric strength, flash point, viscosity, specific gravity and pour point and all of them have to be considered when qualifying new oil as transformer oil [8], $[11,12]$. Moisture in oil is one of a factor that can decrease the life-span of high power transformer [13-15] and the water content in the oil need to be tested periodically. This is because the presence of large water content can causes many problems for a power transformer including electrical breakdown between either its windings or one winding with neutral, increase in the amount of partial discharge and sundry minor problems [13-17]. However, the coconut oil able to absorbs much moisture compare to the mineral oil due to the content of fatty acid in it $[4,6]$. Thus, able to keep cellulose paper in the transformer dry and slowing down the degradation process. In this study, the water absorption in VCO also will be study to see its changes toward the added moisture in oil.

Then, breakdown voltage is one of the important properties to define the efficiency of oil as an insulator $[7,18,19]$. The breakdown voltage of a material is not a definite value. It is referred to as withstand voltage where the probability of failure at a given voltage is so low that it is considered at the moment of designing insulation, with the assurance that the material will not fail at this voltage [20]. The breakdown voltage of oil depends on the water saturation [21, 22]. When the water present in the oil increase, the breakdown voltage will be decreased. Besides, it should be noted that all liquids get more viscous with a decrease in temperature. Low viscosity is more better in order to provide the environment for low resistance to a conventional flow of oil hence proper transformer cooling [20]. From previous research, moisture also has effect on viscosity [12]. Mineral oil which has lower intermolecular forces its viscosity decreases as the moisture content increases. Whereas in case of vegetable oils being low molecular liquids have higher intermolecular forces. Hence its viscosity increases [23]. From another research, three dielectric properties were compared between coconut and virgin coconut oil [1]. Those are breakdown voltage, moisture content and viscosity and the results are shown in Table 1. It can be seen that virgin coconut oil has most potential properties compared to coconut and palm oil because it has high breakdown voltage, low moisture content and low viscosity.

Table 1. Comparison between coconut, virgin coconut and palm oil [1]

\begin{tabular}{lccc}
\hline Dielectric property & Coconut oil & Virgin coconut oil & Palm oil \\
\hline Breakdown voltage $(\mathrm{kV})$ & 18.2 & 43.3 & 34.8 \\
Moisture content $(\%)$ & 4.38 & 1.86 & 1.92 \\
Viscosity (mPas) & 61.75 & 49.5 & 64.8 \\
\hline
\end{tabular}

\section{RESEARCH METHOD}

This project is divided into two parts which are doing the dielectric feasibility study on the virgin coconut oil and compared with mineral oil. The second part is to conduct the dielectric test according to the standard IEC 60296 [8]. The proposed tests to investigate dielectric properties of virgin coconut oil are the breakdown voltage test, water content (Karl Fischer test), and kinematic viscosity. Firstly, the pre-test was carried out using the mineral oil until accurate procedure repeatability data by referring to the standard value of mineral oil dielectric properties. Then, the test procedure was continued by using virgin coconut oil.

\subsection{Oil samples preparation}

Mineral and virgin coconut oils sample is divided into three conditions; dry, normal and moisture. As preparing the sample of the oils as listed in Table 2, some of the samples will undergoes dry process for drying the oil samples, direct collect from drum for normal oil sample and adding moisture process for wet oil condition. The method for drying process is a sample from each type of oil is heat in the vacuum oven at $70^{\circ} \mathrm{C}$ for 24 hours. Then, it is left in vacuum oven to cool down until it reaches room temperature for about 7 hours. The purpose of this process is to reduce the moisture inside the oil. While for normal condition the oil is freshly poured-out of the-container. Then, there are 8 samples of VCO and 4 samples of mineral oil with different moisture concentration. The moisture is increased by adding a desired quantity of distilled water into normal oil sample to achieve required ppm as shown in Table 3. Afterward, the mixture of oil and water is stirred using a magnetic stirrer at constant temperature of $40^{\circ} \mathrm{C}$ for a period of 24 hours for the coconut oil and 48 hours for the mineral oil until all water droplets became visibly absent from the sample [24]. 
Table 2. List of samples condition

\begin{tabular}{ccc}
\hline Type of oil & Sample & Moisture Condition \\
\hline Mineral oil & MD & Dry \\
& MN & Norma \\
& M10 & Normal+10 ppm \\
& M20 & Normal+20 ppm \\
& M30 & Normal+30 ppm \\
& M40 & Normal+40 ppm \\
Virgin coconut oil & VD & Dry \\
& VN & Normal \\
& V10 & Normal+10 ppm \\
& V20 & Normal+20 ppm \\
& V30 & Normal+30 ppm \\
& V40 & Normal+40 ppm \\
& V50 & Normal+50 ppm \\
& V60 & Normal+60 ppm \\
& V80 & Normal+80 ppm \\
& V160 & Normal+160 ppm \\
\hline
\end{tabular}

Table 3. Water addition to normal oil

\begin{tabular}{cccc}
\hline $\begin{array}{c}\text { Type of } \\
\text { oil }\end{array}$ & $\begin{array}{c}\text { Volume of } \\
\text { oil }(\mathrm{ml})\end{array}$ & $\begin{array}{c}\text { Desired water } \\
\text { content }(\mathrm{ppm})\end{array}$ & $\begin{array}{c}\text { Water } \\
\text { added }(\mathrm{ml})\end{array}$ \\
\hline $\begin{array}{c}\text { Minreal } \\
\text { oil }\end{array}$ & 500 & 10 & 0.005 \\
& 500 & 20 & 0.01 \\
& 500 & 30 & 0.015 \\
Virgin & 500 & 40 & 0.02 \\
coconut & 500 & 10 & 0.005 \\
oil & 500 & 20 & 0.01 \\
& 500 & 30 & 0.015 \\
& 500 & 40 & 0.02 \\
& 500 & 50 & 0.025 \\
& 500 & 60 & 0.03 \\
& 500 & 80 & 0.004 \\
& 500 & 160 & 0.008 \\
\hline
\end{tabular}

\subsection{Breakdown voltage}

The test cell uses the standard sphere shape electrode with $12.5 \mathrm{~mm}$ diameter and gap $2.5 \mathrm{~mm}$ apart as shown in Figure 1. Then, the voltage applied to the electrode is increased steadily at the rate $2 \mathrm{kV} / \mathrm{s} \pm$ $0.2 \mathrm{kV} / \mathrm{s}$. The standard unit used for breakdown voltage is BDV $/ \mathrm{mm}$. All the test setup and procedure is arranged by referring to the standardized testing procedures and equipment as referred to IEC60156 standard [25]. In this experiment BA 100 (Portable Breakdown Analyzer) test instrument is used for oil testing. It automatically tests the breakdown strength of liquid dielectric 6 times and measure the sample temperature. After that, the average and standard deviation of breakdown voltage are calculated.

\subsection{Water content}

This test method is to measure the water present in the insulating liquid and it is carried out by following standard ASTM D1533 [26]. It used coulometric Karl Fischer titration because it is known for high

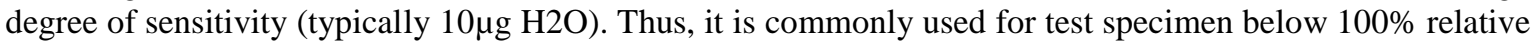
saturation of water in the oil [26]. During the test, the temperature of all the sample should be set at room temperature to see the change of water present in the different water concentration of insulating oil. This is because the changes in temperature will effect the moisture of the sample. Water content in the oil is measured in ppm. In this experiment, instrument CA-21 as shown in Figure 2 is used to measure the water content. It automatically read out the mass of water and calculate the water content. Laboratory balance is used to measure the mass of the sample injected into the reagent solution and the mass is recorded in CA-21.

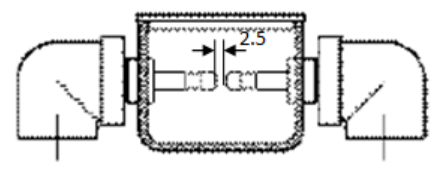

Figure 1. Test cell with spherical electrode used for the breakdown voltage test

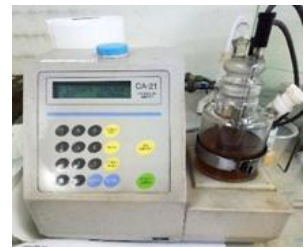

Figure 2. Instrument CA-21 measure water content automatically

\subsection{Kinematic viscosity}

This test method is carried out according to the ASTM D445 Standard Test Method for Kinematic Viscosity of Transparent and Opaque Liquids (and Calculation of Dynamic Viscosity) standard [27]. It specifies a procedure for the determination of the kinematic viscosity, of liquid petroleum products, both transparent and opaque, by measuring the time for a volume of liquid to flow under gravity through a calibrated glass capillary viscometer [27]. Kinematic viscosity is the product of the measured flow time and the calibration constant of the viscometer. Two determined kinematic viscosity values are needed to calculate a viscosity result that is the average of two acceptable determined values. The unit of kinematic viscosity use in this test is cSt. 


\section{RESULTS AND ANALYSIS}

The data obtained from the experiment is recorded and the variation is calculated to see the percentage of variation from normal sample. After that, the graphs are drawn using MATLAB software to analyze the effect of moisture of virgin coconut oil on the breakdown voltage and viscosity. Then, the equation is developed to express the breakdown voltage as a function of increasing moisture for mineral and virgin coconut oil.

\subsection{Breakdown voltage}

Breakdown voltage test is to find the maximum withstand voltage where the probability of failure of insulator at a given voltage value. Therefore, the value of the breakdown voltage should be high as much as possible. From the graph in Figure 3, it can be seen that the breakdown voltage of dry VCO is much higher than mineral oil which is $99.8 \mathrm{kV}$ and $335.808 \%$ higher than the normal VCO. The breakdown voltage of normal VCO is only $22.9 \mathrm{kV}$ and below than $30 \mathrm{kV}$ which does not fulfil the IEC60296 standard. This is because most of the VCO that produce by the local company does not undergoes heating process, chemical-refining, bleaching or deodorizing to retained the fresh aroma, flavour and essential properties of virgin coconut oil. Thus, it can be assumed there is a lot of moisture ingress in the VCO that can lowering the breakdown voltage. The breakdown voltage of normal mineral oil is $67.4 \mathrm{kV}$ which is good and the quality of oil taken from drum is assured for insulation equipment. After the water is added to achieve desired water content, the decline of BDV of mineral oil has higher steep than VCO. However, at $80 \mathrm{ppm}$ the breakdown voltage of VCO start to increase again.

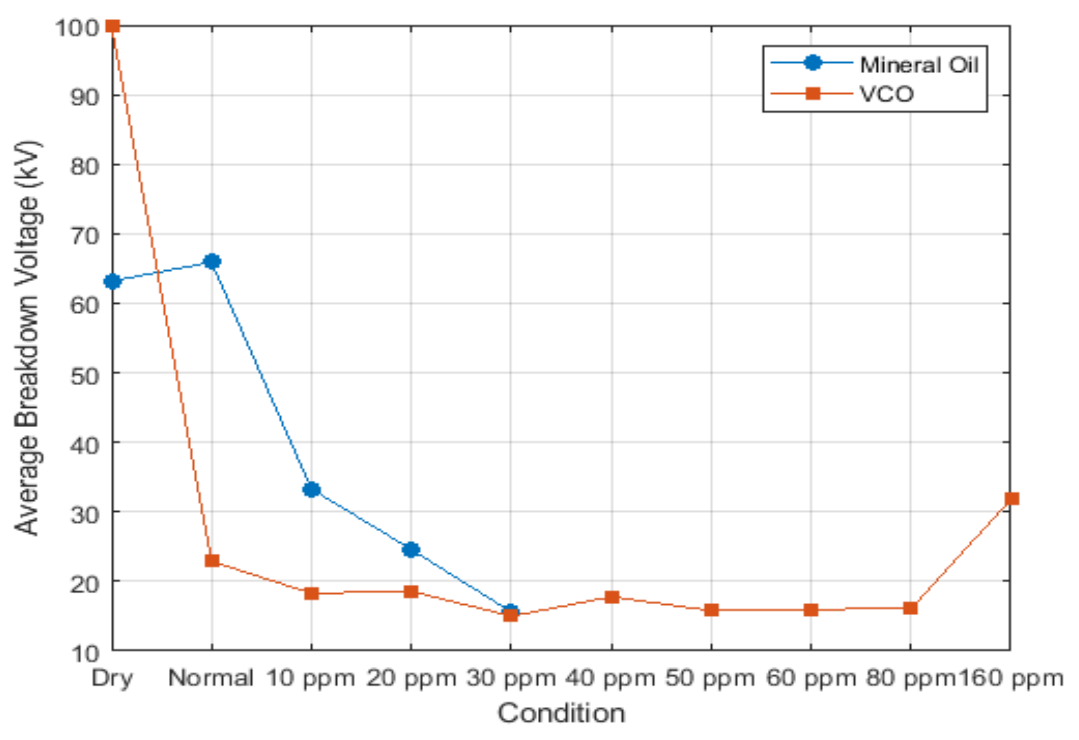

Figure 3. Condition against average of breakdown voltage

\subsection{Water content}

From Figure 4, the water content of VCO is much higher than the mineral oil. For $10 \mathrm{ppm}$, the mineral increased by $17 \mathrm{ppm}$ and VCO increased by $75 \mathrm{ppm}$. Therefore, VCO has an advantage to absorb more moisture from Kraft paper and keep it dry. The Figure 5, shows that moisture between normal VCO and mineral oil is largely difference. After the VCO sample is heated, the moisture is decreased about $76.437 \%$. However, the moisture of mineral oil is increase $41.667 \%$. This is happening probably due to the moisture ingress in mineral oil during the heating process and the vacuum oven has reached its limit to remove moisture from sample. The vacuum oven that has been used only can operate at 1 bar. After some time of moisture removal, the sample would reach the equilibrium moisture content and no more removal moisture would take place. For the mineral oil, the opposite process happens because the moisture is ingress into the sample. If the vapor pressure of the vacuum oven lower, probably the water can be evaporated to reduce moisture or maintain the water content in mineral oil. When $0.005 \mathrm{ml}$ of water is added into each sample to get $10 \mathrm{ppm}$ water content, the result of moisture obtained from the experiment of mineral oil and VCO are $70.833 \%$ and $6.073 \%$ each. This shows that mineral oil is more sensitive toward the moisture compared to $\mathrm{VCO}$.

Virgin coconut oil dielectrical properties as electrical insulation material (Siti Syafiqah Mat Sauki) 


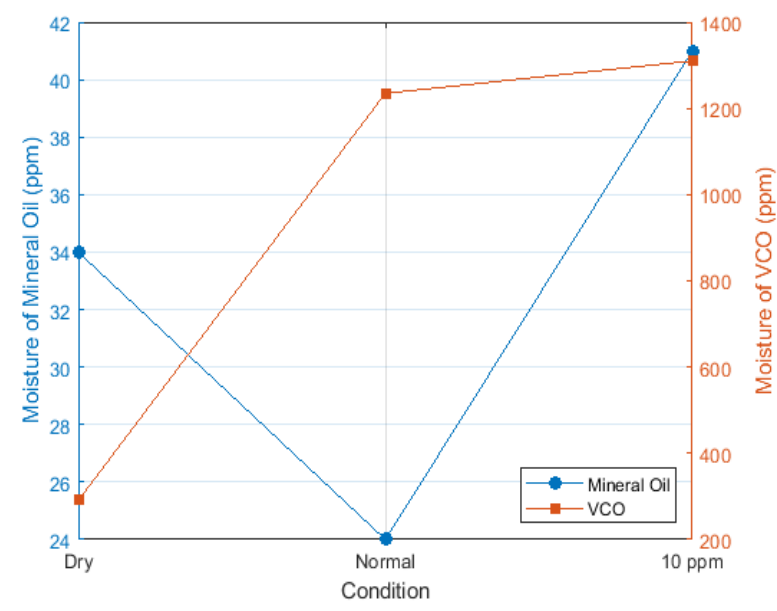

Figure 4. Condition against moisture

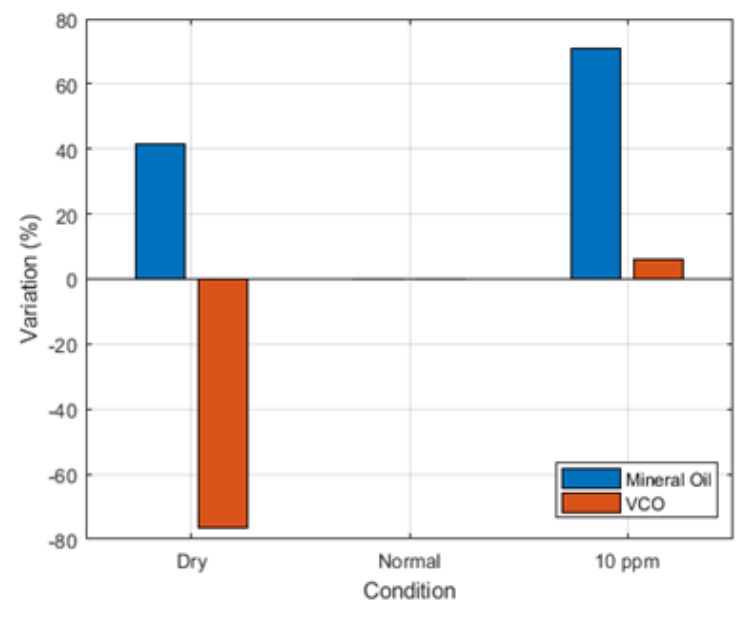

Figure 5. Condition against variation of moisture

\subsection{Kinematic viscosity}

From Figure 6, the mineral oil has lower value of kinematic viscosity. Therefore, in term of viscosity mineral oil is far better because the lower the viscosity, the faster the flow of oil through the transformer windings, core and cooling equipment. Mineral Oil has low intermolecular forces, thus the kinematic viscosity decrease. In contrast, VCO has high intermolecular forces, therefore the viscosity increases. When the moisture change, the kinematic viscosity also slightly changes but it does not significant.

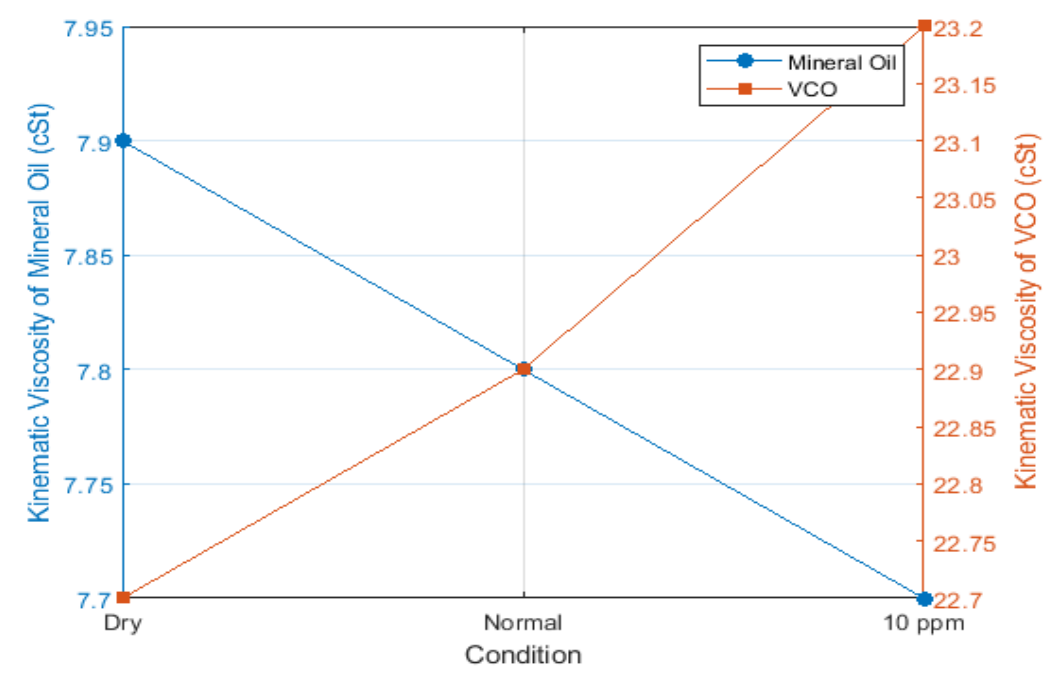

Figure 6. Condition against kinematic viscosity

\subsection{Relationship between moisture, BDV and viscosity}

Figure 7, shows that the breakdown voltage decreases as the moisture increases. The lowest moisture obtained for mineral oil is $24 \mathrm{ppm}$ while for virgin coconut oil the moisture is $291 \mathrm{ppm}$. However, the breakdown voltage of dry VCO is higher than mineral oil which is $99.8 \mathrm{kV}$ even though the moisture of $\mathrm{VCO}$ is much higher than mineral oil. Then, the rate of breakdown voltage decrease with the increasing of moisture in VCO is remarkably lower than mineral oil. In Figure 8, VCO has higher moisture and viscosity. The dry VCO has the moisture value $291 \mathrm{ppm}$ with kinematic viscosity $22.7 \mathrm{cSt}$ while the result for dry mineral oil are $34 \mathrm{ppm}$ and $7.9 \mathrm{cSt}$. Thus, the conclusion that can be made is insulating oil that has higher moisture also has higher viscosity. Then, the slightly changes value of kinematic viscosity obtained from the test when water is added also show that the viscosity does not greatly affect by the moisture and the parameter viscosity is not important when the moisture change. 


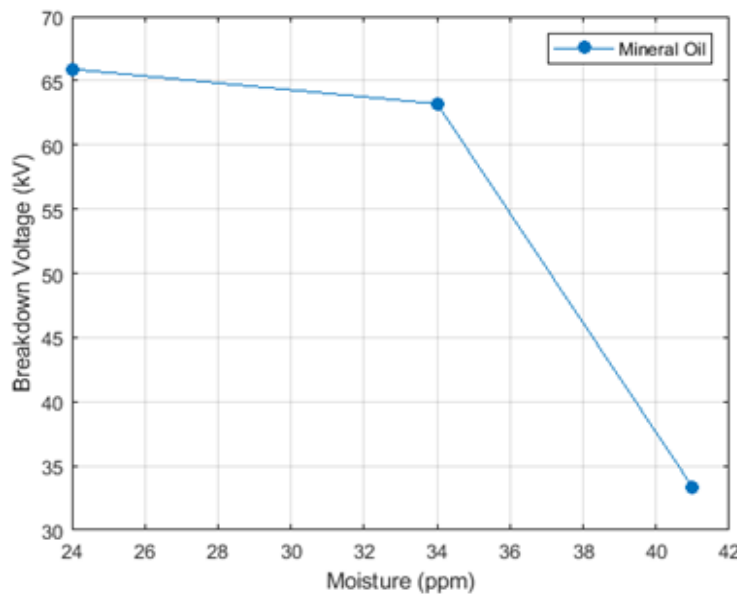

(a)

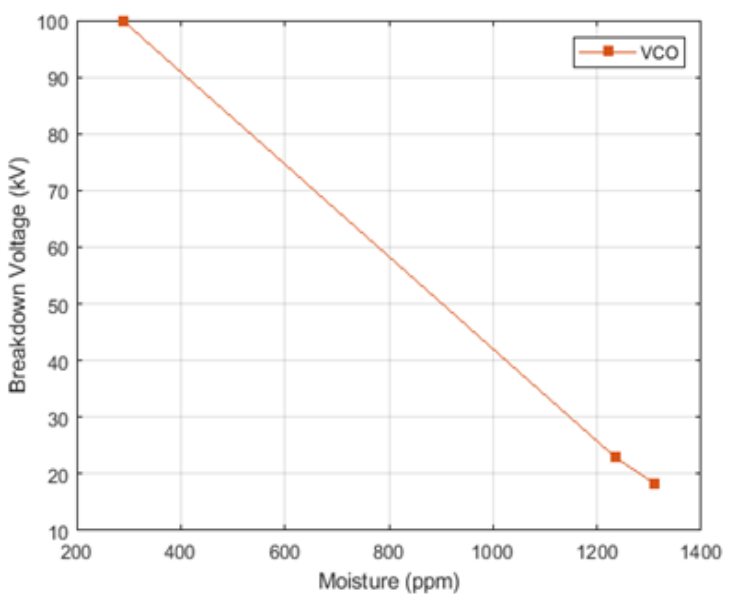

(b)

Figure 7. Moisture against breakdown voltage, (a) Mineral oil, (b) Virgin coconut oil

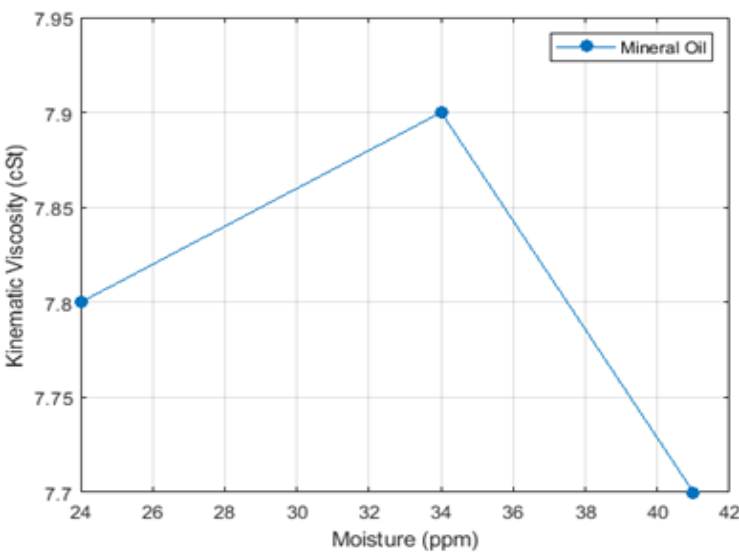

(a)

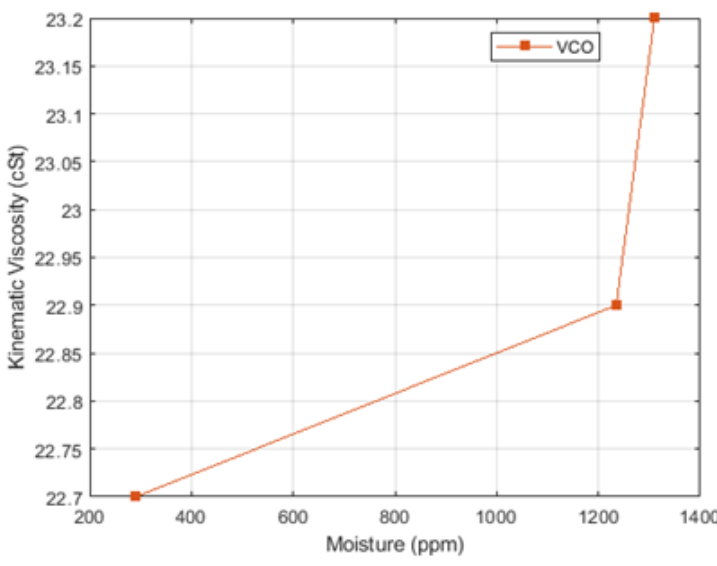

(b)

Figure 8. Moisture against kinematic viscosity, (a) Mineral oil, (b) Virgin coconut oil

\section{CONCLUSION}

In this study, 3 dielectric properties of VCO are investigated. Those are breakdown voltage, water content, kinematic viscosity and the result obtained are $22.9 \mathrm{kvV} 1235 \mathrm{ppm}$ and $22.9 \mathrm{cSt}$ respectively. The result shows that the moisture in VCO is higher than mineral oil. This is likely due to the chemical reaction, oxidization or hydrolyzation in VCO that cause the moisture in oil samples keep increasing until the oil gets saturated by moisture [24]. Then, the breakdown voltage decreases gradually with the increasing of moisture. However, the rate of breakdown voltage decreases with increasing of moisture of VCO was found to be remarkably lower than mineral oil, under similar condition of exposure to the atmosphere. Next, the change of moisture seems to have effects on the viscosity. After dry or adding water into the sample, all the result obtained shows that the kinematic viscosity varied less than $2 \%$ which has very small difference. For mineral oil, as the moisture increase, the viscosity decreases while viscosity for virgin coconut oil increase. This is due to the high intermolecular forces in the VCO. The breakdown voltage is measured using $2.5 \mathrm{~mm}$ sphere gap system under $50 \mathrm{~Hz}$ AC voltages. The highest breakdown voltage obtained from the test conducted for mineral oil is $67.4 \mathrm{kV}$ while dry VCO is $99.8 \mathrm{kV}$. Therefore, in term of breakdown voltage, VCO is far better than mineral oil because the higher the breakdown voltage the lower the percentage of an insulator become electrically conductive. Anyhow, the kinematic viscosity of VCO is very high which is $22.9 \mathrm{cSt}$. This result is not satisfactory because the high viscosity causes the rate of facilitate convection for transformer cooling reduced. In conclusion, VCO has good potential breakdown voltage with the ability to absorb a lot of moisture keeping the Kraft paper dry. However, its kinematic viscosity is very high making it not favorable. 
The lower melting point also causes the VCO only can be used in tropical country. Thus, VCO must undergoes some purification process such as bleaching and deodorization to improve certain properties desired [10].

\section{ACKNOWLEDGEMENTS}

The authors would like to acknowledge gratefully the financial support under grants managed by Ir. Dr. Nor Asiah Binti Muhamad, lecturer at Universiti Sains Malaysia (USM) grant number 1001/PELECT/6315032 1001/PELECT/8014054 and. Then, special thanks to Discharge and Insulation Laboratory, USM for the help in this research.

\section{REFERENCES}

[1] A. A. H. Zaidi, N. Hussin and M. K. M. Jamil, "Experimental study on vegetable oils properties for power transformer," 2015 IEEE Conference on Energy Conversion (CENCON), Johor Bahru, 2015, pp. 349-353.

[2] D. M. Mehta, P. Kundu, A. Chowdhury, V. K. Lakhiani and A. S. Jhala, "A review of critical evaluation of natural ester vis-a-vis mineral oil insulating liquid for use in transformers: Part II," in IEEE Transactions on Dielectrics and Electrical Insulation, vol. 23, no. 3, pp. 1705-1712, June 2016.

[3] D. M. Mehta, P. Kundu, A. Chowdhury, V. K. Lakhiani and A. S. Jhala, "A review on critical evaluation of natural ester vis-a-vis mineral oil insulating liquid for use in transformers: Part 1," in IEEE Transactions on Dielectrics and Electrical Insulation, vol. 23, no. 2, pp. 873-880, April 2016.

[4] W. M. L. B. Naranpanawe, M. A. R. M. Fernando, J. R. S. S. Kumara, E. M. S. N. Naramapanawa and C. S. Kalpage, "Performance analysis of natural esters as transformer liquid insulation-Coconut, castor and sesame oils," 2013 IEEE 8th International Conference on Industrial and Information Systems, Peradeniya, 2013, pp. 105-109.

[5] Kurnianto, R., et al. "Breakdown strength of biodegradable dielectric liquid: The effect of temperature and viscosity". in 2012 22nd Australasian Universities Power Engineering Conference (AUPEC). 2012.

[6] B. S. H. M. S. Y. Matharage, M. A. R. M. Fernando, M. A. A. P. Bandara, G. A. Jayantha and C. S. Kalpage, "Performance of coconut oil as an alternative transformer liquid insulation," in IEEE Transactions on Dielectrics and Electrical Insulation, vol. 20, no. 3, pp. 887-898, June 2013.

[7] S. S. Sinan, J. Jasni, N. Azis, M. Z. A. A. Kadir and M. N. Mohtar, "Assessment on the AC breakdown voltages of liquid insulation system," 2015 IEEE International Circuits and Systems Symposium (ICSyS), Langkawi, 2015, pp. $155-158$.

[8] 60296, I., Fluids for electrotechnical applications-Unused mineral insulating oils for transformer and switchgear. 2012.

[9] Lucas, R., et al., Coconut Oil Insulated Distribution Transformer. 2002.

[10] D. C. Abeysundara, C.W., R. Lucas, K. A. I. Gunatunga, and K. C. Obadage, "Coconut oil as an alternative to transformer oil". 2001.

[11] A.A.H. Zaidi et al., "Efficiency Improvement of Single Phase Transformer Using Virgin Coconut Oil", Applied Mechanics and Materials, Vol. 793, pp. 187-191, 2015.

[12] Ariffin, M.M., et al. "Ageing effect of vegetable oils impregnated paper in transformer application". in 2017 International Conference on High Voltage Engineering and Power Systems (ICHVEPS). 2017.

[13] Jongvilaikasen, K., et al. "Different Moisture Contents of Pressboard Effect on Electrical and Chemical Characteristics of Liquid Insulation". in 2018 Condition Monitoring and Diagnosis (CMD). 2018.

[14] C. Krause, P. Brupbacher, A. Fehlmann and B. Heinrich, "Moisture effects on the electric strength of oil/pressboard insulation used in power transformers," IEEE International Conference on Dielectric Liquids, 2005. ICDL 2005., Coimbra, Portugal, 2005, pp. 369-372.

[15] Qin, C., et al., "Experimental Study on Breakdown Characteristics of Transformer Oil Influenced by Bubbles". Energies, 2018. 11: p. 634.

[16] Sone, M. and H. Mitsui. "Effect of water in Kraft-paper impregnated oil on breakdown". in 1988. Annual Report., Conference on Electrical Insulation and Dielectric Phenomena. 1988.

[17] V. Sarfi, S. Mohajeryami and A. Majzoobi, "Estimation of water content in a power transformer using moisture dynamic measurement of its oil," in High Voltage, vol. 2, no. 1, pp. 11-16, 32017.

[18] Akca, H., et al., "Breakdown Strength Analysis of the Transformer Insulation Oil Due To Different Standards". Conference: International Symposium on High Voltage Engineering (ISH 2013). 2013.

[19] Chmura, L.A., et al. "Time-to-breakdown and breakdown voltage for oil-impregnated insulation subjected to thermal aging". in 2012 International Conference on High Voltage Engineering and Application. 2012.

[20] D. N. Tanteh, S.Y.A.-L., and D. Ssekasiko, "Properties of transformer oil that affect efficiency". in Student Thesis. 2014.

[21] Yilmaz, H. and S. Guler. "The effect of electrode shape, gap and moisture on dielectric breakdown of transformer oil”. in ICDL'96. 12th International Conference on Conduction and Breakdown in Dielectric Liquids. 1996.

[22] Murad, N.S., et al. "A study on palm oil-based oil moisture absorption level and voltage breakdown". in 2013 Annual Report Conference on Electrical Insulation and Dielectric Phenomena. 2013. 
[23] S. D. M., C.B., F. Valentina, P. B. S., "Comparative Study of Breakdown Phenomena and Viscosity". in Liquid Dielectrics. 2017. Vol. 5.

[24] A. A. Suleiman, N. A. Muhamad, N. Bashir, N. S. Murad, Y. Z. Arief and B. T. Phung, "Effect of moisture on breakdown voltage and structure of palm based insulation oils," in IEEE Transactions on Dielectrics and Electrical Insulation, vol. 21, no. 5, pp. 2119-2126, Oct. 2014.

[25] 60156, I., Insulating Liquids-Determination of the Breakdown Voltage at Power Frequency-Test Method. 2018, IEC: Webstore International Electrotechnical Commission.

[26] D1533, A., Standard Test Method for Water in Insulating Liquids by Coulometric Karl Fischer Titration. 2005.

[27] D445, A., Standard Test Method for Kinematic Viscosity of Transparent and Opaque Liquids (and Calculation of Dynamic Viscosity) 2006.

\section{BIOGRAPHIES OF AUTHORS}
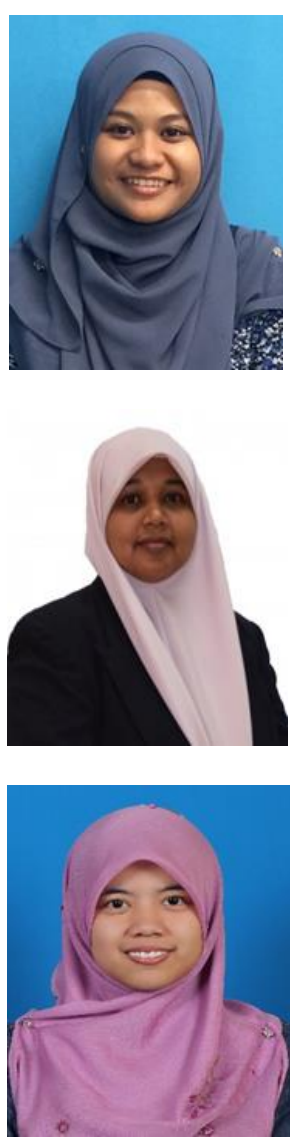

Siti Syafiqah Mat Sauki received her Bachelor's degree in Electrical Engineering from Universiti Sains Malaysia in 2018. Currently, she works as electrical design engineer and draughtman for wholly-owned subsidiary of offshore drilling company in Penang.

Nor Asiah Muhamad (M'13) is currently serving as Senior Lecturer at the School of Electrical and Electronic Engineering, Universiti Sains Malaysia. Previously, she was a researcher and senior lecturer at the Institute of High Voltage and High Current (IVAT) in Faculty of Electrical Engineering, Universiti Teknologi Malaysia for 13 years. She obtained her Ph.D degree in 2009 from University of New South Wales, Australia. She received her Bachelor's degree in Electrical and Electronic Engineering from Universiti Teknologi Petronas, Malaysia, in 2002 and Master's Degree in Electrical Power Engineering from University of South Australia in 2006. Her research interest is centred on power system equipment monitoring, in particular, insulation diagnosis and the development of new systems for condition monitoring.

Zawani Amirah Rasid received her B.Eng. and M.Eng degree in electrical engineering from Universiti Teknologi Malaysia in 2013 and 2015, respectively. She is currently serving as Research Officer at the School of Electrical Electronic Engineering, Universiti Sains Malaysia and at the same time doing preparation to continue her study in Ph.D level. Her research study include electrical insulation, power equipment and insulation conditioning monitoring. 